\title{
Designing of Learning by Analogy on an Elastic Heat Engine as an Enrichment Material in Senior High School
}

\author{
Nurhidayah Muharayu $^{1, a}$, Widayani ${ }^{1,2, b}$, Risa Suryana ${ }^{3, c}$, Khairurrijal ${ }^{1,2, d}$ \\ ${ }^{1}$ Master Program in Physics Teaching, Faculty of Mathematics and Natural Sciences, Institut Teknologi Bandung, \\ Jalan Ganesa 10, Bandung 40132, Indonesia \\ ${ }^{2}$ Department of Physics, Faculty of Mathematics and Natural Sciences, Institut Teknologi Bandung, \\ Jalan Ganesa 10, Bandung 40132, Indonesia \\ ${ }^{3}$ Department of Physics, Faculty of Mathematics and Natural Sciences, Universitas Sebelas Maret, \\ Jalan Ir. Sutami 36A, Surakarta 57126, Indonesia \\ a muharayu@gmail.com, ${ }^{\mathrm{b}}$ widayani@fi.itb.ac.id, ${ }^{\mathrm{c}}$ suruyana@ gmail.com, ${ }^{\mathrm{d}}$ krijal@ fi.itb.ac.id
}

\begin{abstract}
Learning by analogy is one method that can be used by a teacher to develop student's creativity in learning. Analogy is a comparison of similarities between two concepts. Thermodynamics is one of the teaching materials covered in the Indonesian senior high school physics curriculum. The concept of ideal gas heat engine (Carnot engine) is already known by the students after their teacher have delivered the thermodynamics material. The concept of ideal gas heat engine is then compared with the target concept an elastic heat engine, to obtain desired attributes. Students are expected to understand that the heat engine concept is applicable for elastic materials, i.e., a system involving elastic materials can changes heat to mechanical work. The method used in this case is developed by Glynn, which is called as TWA (Teaching with Analogy). The stages of the method are as follows: 1) A teacher introduces the target concept (elastic heat engine); 2) Students complete a review about the analogy concept (the Carnot engine); 3) Students identify relevant attributes between the target and analogy. Attributes are: the equation of state, internal energy, heat capacity, and Carnot cycle; 4) Students map the similarity between the analogy and target concepts; 5) Students identify/look for exceptional circumstances where the analogy does not work; 6) Students make the conclusions about the target concepts. The results are then evaluated by the teacher to determine the achievements of students towards the concept of elastic heat engine.
\end{abstract}

Index Terms: Learning by Analogy, Carnot Cycle, Elastic Heat Engine, Teaching with Analogy

\section{Introduction}

Introducing new ideas or concepts can be easier by relating them with other previously understood ideas/concepts. The human ability to link an event with similar events to see similarities between them is called the analogy capabilities [1]. New concepts are often complex and sometimes related to abstract phenomena and abstract systems-which make a teacher facing difficulties to explain them to students. With analogies, students are helped to build their own understanding about new concepts from well-known and general concepts [2]. The use of analogy to understand an abstract phenomenon using the concrete reference has been discussed [3-4]. Several examples of teaching with analogies have been applied at senior high school in the concepts of electromagnetic waves [5], electrical components [6], and electric field [7]. Fortunately, in the examples, both target and analogy concepts are included in the 2013 senior high school physics curriculum [8]. However, there is no report when the target or analogy concept is not in the curriculum.
One of learning materials that can be developed in learning by analogy is thermodynamics. The topic on a Carnot heat engine using an ideal gas is included in the curriculum. Theoretically, Carnot heat engine has the highest efficiency among others with the same cold and hot temperatures. The Carnot cycle is a cycle consisting two isothermal processes and two adiabatic processes [9]. Another engine that could be analogous to the Carnot heat engine is an elastic heat engine using an elastic material. The elastic heat engine could be introduced as an enrichment material in discussing the Carnot heat engine, and designed to make students more active in learning.

This paper will discuss the design of learning by analogy on the Carnot heat engine using an elastic material. The analogy concept is therefore the Carnot heat engine using an ideal gas.

\section{Methodology}

An analogy is a way of human communication by comparing two similar phenomena that may be either literal or figurative. A literal analogy compares two things that are quite similar, while a figurative analogy makes a comparison between things that are more different than identical [10]. Analogies used in classrooms should be designed to promote elaboration, which is the cognitive process of constructing relations between what is already known and what is new [11]. Noting that elaboration plays a critical role in a constructivist framework for learning science, it can be activated by questions, objectives, personal examples, and other strategies [4].

The methodology used to obtain good analogies refers to the model of teaching with analogies (TWA) from Glynn [3]. Based on the TWA Glynn model, there are six steps that must be carried out by students in order to obtain a good analogy [12].

a) A teacher introduces the target concept.

The target concept is a new concept that is not well understood by students.

b) Students complete a review about the analogy concept.

The analogy concept is a common concept that is well known by the students.

c) Students identify relevant attributes between target and analogy concepts.

All attributes of both target and analogy concepts are collected. 
d) Students map similarities between target and analogy concepts.

Connecting similar attributes of the target and analogy concepts is called as mapping. If there are many similar attributes, the obtained analogy is good.

e) Students identify/look for exceptional circumstances where analogies do not work.

f) Students make the conclusions about target concepts. The results will be evaluated by the teacher to determine achievements to the students towards the target concept.

\section{Results and Discussion}

Following the TWA Glynn model, designing of learning by analogy on an elastic heat engine in senior high school can be described in the following six steps.

a) A teacher introduces the target concept.

Carnot heat engine is a heat engine operating in the reversible Carnot cycle [9] and the conventional Carnot heat engine uses an ideal gas. By analogy, other phases of substances either solid or liquid could replace the ideal gas to make another Carnot heat engine. Under a "thought experiment", a Carnot heat engine using an elastic material could be realized and this hypothetical engine is called as an elastic heat engine.

The target concept is therefore the concept of Carnot heat engine using an elastic material, which will be called as an elastic heat engine.

b) Students complete a review about the analogy concept.

The Carnot heat engine using an ideal gas that has been recognized by the students is as the analogy concept because it is included in the 2013 senior high school physics curriculum. Although some important formulas are given in the curriculum, their derivations are still not familiar to the students.

1) The equation of state of an ideal gas is written as $P V=n R T$, where $P$ is pressure, $V$ is volume, $n$ is the mole number of gas, $T$ is temperature in Kelvin, and $R$ is the universal gas constant [9]. The variables $P$ and $V$ are attributed as generalized force and spatial coordinate, respectively, while $T$ is called as an intensive coordinate.

2) Using the first law of thermodynamics $d U=đ Q+$ $\mathrm{d} W$, where $d U$ is the exact differential of internal energy $U$, and $₫ Q$ and $₫ W$ are the inexact differentials of heat and work, respectively, and noting that the adiabatic process is a process when there is no heat exchange from system to environment so that $\mathrm{đQ}=0$, then it is obtained $\mathrm{dU}=\mathrm{d} W$.

3) For a hydrostatic system, the inexact differential of work in changing its volume is given by $\mathrm{d} W=$ $-P d V$ and the first law of thermodynamics becomes $d U=đ Q-P d V$ or $₫ Q=d U+P d V$.

4) Moreover, the inexact differential of heat can further be written as $₫ Q=\left(\frac{\partial U}{\partial T}\right)_{V} d T+\left(\frac{\partial U}{\partial V}\right)_{T} d V+P d V$.
Dividing by $d T$, we get $\frac{\mathrm{d} Q}{d T}=\left(\frac{\partial U}{\partial T}\right)_{V}+\left(\frac{\partial U}{\partial V}\right)_{T} \frac{d V}{d T}+$ $P \frac{d V}{d T}$.

5) If volume $V$ is constant, thendV=0, and $\left(\frac{\mathrm{d} Q}{d T}\right)_{V}=$ $\left(\frac{\partial U}{\partial T}\right)_{V}$

6) By definition, the heat capacity at constant volume $C_{V}=\left(\frac{\mathrm{d} Q}{d T}\right)_{V}$, therefore, $C_{V}=\left(\frac{\partial U}{\partial T}\right)_{V}$.

7) In the special case of the ideal gas in the hydrostatic system, $U$ is a function of $T$ only, therefore $C_{V}=$ $d U / d T$ or $d U=C_{V} d T$.

8) If pressure $P$ is constant and noting that $\frac{\mathrm{d} Q}{d T}=$ $\left(\frac{\partial U}{\partial T}\right)_{V}+\left(\frac{\partial U}{\partial V}\right)_{T} \frac{d V}{d T}+P \frac{d V}{d T}$, then $\left(\frac{d Q}{d T}\right)_{P}=\left(\frac{\partial U}{\partial T}\right)_{V}+$ $\left(\frac{\partial U}{\partial V}\right)_{T}\left(\frac{\partial V}{\partial T}\right)_{P}+P\left(\frac{\partial V}{\partial T}\right)_{P}$

9) By definition, the heat capacity at constant pressure $C_{P}=\left(\frac{\mathrm{d} Q}{d T}\right)_{P}$ and $\left(\frac{\partial V}{\partial T}\right)_{P}=V \beta$, therefore, $C_{P}=$ $C_{V}+\left(\frac{\partial U}{\partial V}\right)_{T} V \beta+P V \beta$, where $\beta$ is the volume expansivity.

10) In the special case of the ideal gas in the hydrostatic system, $U$ is a function of $T$ only, therefore $C_{P}=$ $C_{V}+n R$.

11) Defining the ratio of the heat capacities by the symbol $\gamma$, we have $\gamma=C_{P} / C_{V}$ higher than 1 .

c) Students identify relevant attributes between target and analogy.

Both the target and analogy have features called as attributes. The relevant attributes are the equation of state, generalized force, generalized coordinate, internal energy, heat capacity, work, and Carnot cycle. Students compare and analyze them.

1) In analogy to the ideal gas, the elastic material should also have the equation of state written as [9,13-15]

$\tau=K T\left(\frac{L}{L_{0}}-\left(\frac{L_{0}}{L}\right)^{2}\right)$

where $\tau$ is tension and $L_{0}$ is initial length, $L$ is length (under tension), $K$ is the constant (depend on temperature of elastic material), and $T$ is the temperature. The variables $\tau$ and $L$ are attributed as generalized force and coordinate, respectively.

2) For an elastic wire, the inexact differential of work in changing its length is given by $\mathrm{d} W=\tau d L$ and the first law of thermodynamics becomes $d U=$ $\mathrm{đ} Q+\tau d L$ or $₫ Q=d U-\tau d L$.

3) Moreover, the inexact differential of heat can further be written as $\mathrm{đ} Q=\left(\frac{\partial U}{\partial T}\right)_{L} d T+\left(\frac{\partial U}{\partial L}\right)_{T} d L-\tau d L$. Dividing by $d T$, we get $\frac{\AA Q}{d T}=\left(\frac{\partial U}{\partial T}\right)_{L}+\left(\frac{\partial U}{\partial L}\right)_{T} \frac{d L}{d T}-$ $\tau \frac{d L}{d T}$. 
4) If length $L$ is constant, then $d L=0$, and $\left(\frac{đ Q}{d T}\right)_{L}=$ $\left(\frac{\partial U}{\partial T}\right)_{L}$

5) By definition, the heat capacity at constant length $C_{L}=\left(\frac{\mathrm{d} Q}{d T}\right)_{L}$, therefore, $C_{L}=\left(\frac{\partial U}{\partial T}\right)_{L}$.

6) In the special case of the ideal elastic wire, $U$ is a function of $T$ only, therefore $C_{L}=d U / d T$ or $d U=C_{L} d T$.

7) If tension $\tau$ is constant and noting that $\frac{\mathrm{d} Q}{d T}=\left(\frac{\partial U}{\partial T}\right)_{L}+$ $\left(\frac{\partial U}{\partial L}\right)_{T} \frac{d L}{d T}-\tau \frac{d L}{d T}$ then $\left(\frac{\mathrm{d} Q}{d T}\right)_{\tau}=\left(\frac{\partial U}{\partial T}\right)_{L}+\left(\frac{\partial U}{\partial L}\right)_{T}\left(\frac{\partial L}{\partial T}\right)_{\tau}-\tau\left(\frac{\partial L}{\partial T}\right)_{\tau}$.

8) By definition, the heat capacity at constant pressure $C_{\tau}=\left(\frac{\mathrm{d} Q}{d T}\right)_{\tau}$ and $\left(\frac{\partial L}{\partial T}\right)_{\tau}=L \beta_{L}$, therefore, $C_{\tau}=$ $C_{L}+\left(\frac{\partial U}{\partial L}\right)_{T} L \beta_{L}-\tau L \beta_{L}$, where $\beta_{L}$ is the length expansivity.

9) In the special case of the ideal elastic wire, $U$ is a function of $T$ only, therefore $C_{\tau}=C_{L}-\tau L \beta_{L}$.

10) Defining the ratio of the heat capacities by the symbol $\gamma$, we have $\gamma=C_{\tau} / C_{L}$ higher than 1 .

d) Students map similarities between target and analogy concepts.

Students map similar attributes as many as possible in order to obtain good analogy. The similarities of the Carnot heat engine and the elastic heat engine that have been mapped are listed in Table 1 and given in Figs. 1 and 2.

Table 1. The comparison of physical properties between an ideal gas and elastic material.

\begin{tabular}{|l|c|c|}
\hline \multicolumn{1}{|c|}{ Variables } & Ideal Gas & Elastic Substance \\
\hline Generalized Force & Pressure $(\mathrm{P})$ & Tension $(\tau)$ \\
\hline Generalized Coordinate & Volume $(\mathrm{V})$ & Length $(L)$ \\
\hline Intensive Coordinate & Temperature $(\mathrm{T})$ & Temperature $(\mathrm{T})$ \\
\hline Equation of State & $P V=n R T$ & $\tau=K T\left(\frac{L}{L_{0}}-\frac{L_{0}{ }^{2}}{L^{2}}\right)$ \\
\hline Internal Energy & $\mathrm{U}=\mathrm{U}(\mathrm{T})$ & $\mathrm{U}=\mathrm{U}(\mathrm{T})$ \\
\hline Heat Capacity & $C_{V}=\left(\frac{d Q}{d T}\right)_{V}$ & $C_{L}=\left(\frac{d Q}{d T}\right)_{L}$ \\
& $C_{P}=\left(\frac{d Q}{d T}\right)_{P}$ & $C_{\tau}=\left(\frac{d Q}{d T}\right)_{\tau}$ \\
\hline Work & $W=-\int P d V$ & $W=\int \tau d L$ \\
\hline
\end{tabular}

The Carnot cycle of the Carnot heat engine using the ideal gas is represented in Fig. 1 [9]. There are four lines: i) reversible isothermal expansion, ii) reversible isothermal compression, iii) reversible adiabatic expansion, and iv) reversible adiabatic compression.

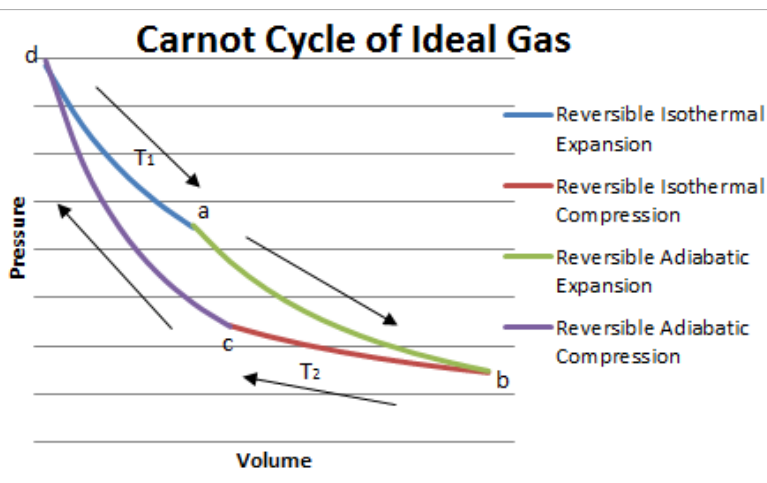

Figure 1. PV diagram of Carnot cycle.

In order to obtain the Carnot cycle of the elastic heat engine, the equation of state in Eq. (1) is used along with the first law of thermodynamics.

\section{a. Isothermal Process}

For a small addition of length $(\Delta L)$, so $L \rightarrow L_{0}$, the tension in Eq. (1) is approximated by using Taylor series,

$\tau(L)=\tau\left(L_{0}+\Delta L\right)=\left.\tau\left(L_{0}\right)\right|_{L_{0}}+\left.\frac{\tau \prime\left(L_{0}\right) \Delta L}{1 !}\right|_{L_{0}}+R\left(O^{2}\right)$.

(2)

Substituting Eq. (1) into Eq. (2), it is obtained

$$
\begin{aligned}
& \left.\tau(L) \cong K T\left(\frac{L}{L_{0}}-\left(\frac{L_{0}}{L}\right)^{2}\right)\right|_{L_{0}}+\left.K T\left(\frac{1}{L_{0}}+\frac{2 L_{0}{ }^{2}}{L^{3}}\right) \Delta L\right|_{L_{0}}, \\
& \tau(L) \cong K T(1-1)+K T\left(\frac{1}{L_{0}}+\frac{2 L_{0}{ }^{2}}{L_{0}{ }^{3}}\right)\left(L-L_{0}\right), \\
& \tau(L) \cong K T\left(\frac{1}{L_{0}}+\frac{2}{L_{0}}\right)\left(L-L_{0}\right), \\
& \tau(L) \cong K T\left(\frac{3 L}{L_{0}}-3\right)=3 K T\left(\frac{L}{L_{0}}-1\right) .
\end{aligned}
$$

So, for a small addition of length $(\Delta L)$, the relation between $\tau$ and $\mathrm{L}$ becomes

$$
\tau(L)=3 K T\left(\frac{L}{L_{0}}-1\right)
$$

For the isothermal process, in which $T$ is a constant $c$, the equation of state in Eq. (3) becomes

$$
\tau=c\left(3 K\left(\frac{L}{L_{0}}-1\right)\right)
$$

\section{b. Adiabatic Process}

Using the first law of thermodynamics $d U=đ Q+₫ W$, where $d U$ is the exact differential of internal energy $U$, and $₫ Q$ and $₫ W$ are the inexact differentials of heat and work, respectively, and noting that the adiabatic process is a process when there is no heat exchange from system to environment so that $₫ Q=0$, then it is obtained

$$
d U=\mathrm{d} W
$$

From the first law of thermodynamic, we know

$$
đ Q=d U-\tau d L
$$




$$
\begin{aligned}
\text { đ } Q & =C_{L} d T-\tau d L \\
\text { đ } Q & =C_{L} d T-\tau\left[\left(\frac{\partial L}{\partial T}\right)_{\tau} d T+\left(\frac{\partial L}{\partial \tau}\right)_{T} d \tau\right] \\
\text { đ } Q & =C_{L} d T-\tau\left(\frac{\partial L}{\partial T}\right)_{\tau} d T-\tau\left(\frac{\partial L}{\partial \tau}\right)_{T} d \tau \\
\text { đ } Q & =\left(C_{L}-\tau L \beta_{L}\right) d T-\tau \frac{L}{Y A} d \tau \\
\text { đ } Q & =C_{\tau} d T-\alpha L d \tau
\end{aligned}
$$

where $d L=\left(\frac{\partial L}{\partial T}\right)_{\tau} d T+\left(\frac{\partial L}{\partial \tau}\right)_{T} d \tau$ and $\left(\frac{\partial L}{\partial \tau}\right)_{T}=\frac{L}{Y A} . \quad Y$ is isothermal Young's modulus $\left(\mathrm{N} / \mathrm{m}^{2}\right), A$ denotes the crosssectional area $\left(\mathrm{m}^{2}\right), \tau$ is the tension $(\mathrm{N})$, and $\alpha=\frac{\tau}{Y A}$ is constant.

because đQ $Q=0$, therefore Eqs. (6) and (7) become,

$$
\begin{gathered}
C_{L} d T=\tau d L \\
C_{\tau} d T=\alpha L d \tau
\end{gathered}
$$

From the following equations are obtained,

$$
\begin{aligned}
d T & =d T \\
\frac{C_{L}}{\tau d L} & =\frac{C_{\tau}}{d \tau} \frac{1}{\alpha L} \\
\int \frac{d \tau}{\tau} & =\frac{C_{\tau}}{C_{L}} \int \frac{d L}{L} \\
\ln \tau & =\frac{C_{\tau}}{C_{L}} \ln L \\
\tau \quad & =L^{\frac{C_{\tau}}{C_{L}}} \\
\tau L^{-\frac{C_{\tau}}{C_{L}}} & =a
\end{aligned}
$$

where $a$ is a constant and $\frac{C_{\tau}}{C_{L}}=\gamma$, where $\gamma>1$.

Since Eq. (4) represents the isothermal process and Eq. (8) does the adiabatic process, a Carnot cycle of the elastic heat engine is demonstrated in Fig. 2.

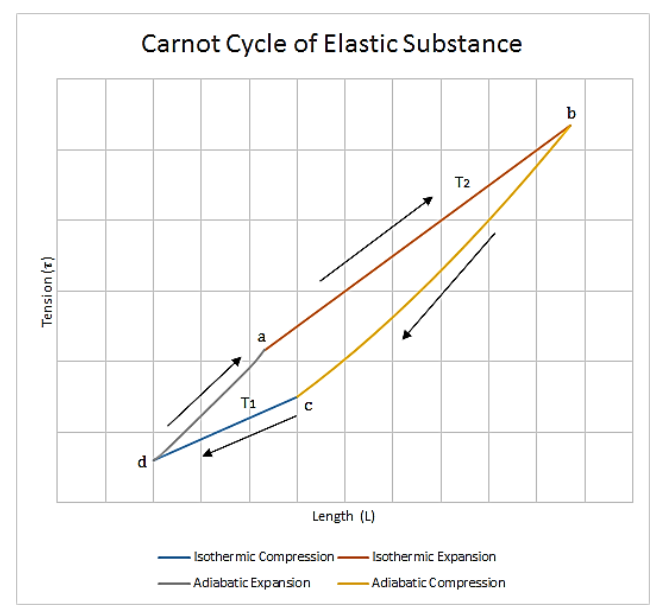

Figure 2. Carnot Cycle of an elastic heat engine using an elastic material.

e) Students identify/look for exceptional circumstances where analogies do not work.

The concept of ideal gas heat engine can be used for analogy of elastic heat engine with exception in minus sign of work. f) Students make conclusions about the target concepts. Various results will be obtained by students. The results will be evaluated by the teacher to determine achievements to the students towards the elastic heat engine concept.

\section{Conclusion}

A material of learning by analogy in senior high school has been designed. There are analogies between ideal gas heat engine and elastic heat engine. The concepts cover equation of state, internal energy, heat capacity, work, and Carnot cycle. In this analogy, generalized force $P$ for ideal gas is proportional with temperature but inversely proportional with its generalized coordinate $V$. While generalized force $\tau$ for elastic material is not only proportional with temperature but also its generalized coordinate $L$. The constants used are $R$ and $K$ for ideal gas and elastic material equation of states, respectively. In addition, the work for both ideal gas and elastic material can be defined as integral of the product between generalized forces with the changes in generalized coordinate.

\section{References}

[1] Soekadijo in R. Rahman and S. Maarif, "Pengaruh penggunaan metode discovery terhadap kemampuan analogi matematis siswa SMK Al-Ikhsan pamarican kabupaten Ciamis Jawa Barat," J. Ilmiah Program Studi Matematika STKIP Siliwangi Bandung, vol 3, no.1, 2014.

[2] S. M. Glynn, "Teaching science with analogy: A strategy for teachers and textbook authors," National Reading Research Center Universities of Georgia and Maryland Reading Research Report no. $15,1994$.

[3] A. G Harisson and D. F Treagust, "Teaching with analogies: A case study in grade-10 Optics," J. Research in Science Teaching vol. 30, no. 10,1993 , pp. 1291-1307.

[4] S. M Glynn, "Making science concepts meaningful to students: teaching with analogies," 2008, pp. 114-125.

[5] Widayani, et al, "Pemahaman konsep gelombang elektromagnetik dengan analogi terhadap konsep gelombang mekanik, " J. Pengajaran Fisika untuk Sekolah Menengah, vol. 1, no. 4, 2009, pp. 100-104.

[6] Khairurrijal, et al, "Konsep komponen listrik (kapasitor, induktor, dan memristor) menggunakan analogi konsep resistor untuk pengajaran di sekolah menengah atas," J. Pengajaran Fisika Sekolah Menengah, vol. 1, no. 4, 2009, pp. 91-95.

[7] Khairurrijal, et al, "Konsep medan listrik menggunakan analogi konsep medan gravitasi untuk pengajaran di sekolah menengah atas," J. Pengajaran Fisika Sekolah Menengah, vol. 1, no. 3, 2009, pp. 7881.

[8] Kementrian Pendidikan dan Kebudayaan, "Kurikulum 2013 Sekolah Menengah Atas (SMA)/Madrasah Aliyah (MA)," Jakarta: Kemendikbud, 2013.

[9] M. W. Zemansky and R. H. Dittman, Heat and Thermodynamics, $7^{\text {th }}$ ed., Singapore: McGraw Hill, 1997.

[10] R. M. Carter and S. L. Tubbs, "Supporting materials for public communication", in Shared Experiences in Human Communication, S. L. Tubbs and R. M. Carter (eds.), Transaction Publishers, 1978, pp. 199-202.

[11] R. Duit and S. M. Glynn, "Analogien - Brücken zum Verständnis. (Analogies bridges to understanding)," J. Naturwissenschaften im Unterricht-Physik, vol.27, no. 6, 1995, pp. 4-10.

[12] S. M. Glynn, "Explaining science concepts: A teaching-withanalogies model," in The psychology of learning science, S. M. Glynn, R. H. Yeany, and B. K. Britton (Eds.), Hillsdale, NJ: Erlbaum, 1991, pp. 219-240.

[13] J. Pellicer, J. A. Manzanares, and S. Mafe, "Ideal systems in classical thermodynamics," Eur. J. Phys. 18, 1997, pp. 269-273.

[14] V. Talanquer,"Reclaiming the central role of equations of state in thermodynamics," J. Chem. Educ., vol. 83, no. 1, pp. 127-131, 2006.

[15] Y. Galperin, Problems for the Course Statistical Physics, p. 14, 2004. 